National

Academy

of

Sciences

National Research Council

NUCLEAR SCIENCE SERIES

The Radiochemistry of the Transcurium Elements 


\section{COMMITTEE ON NUCLEAR SCIENCE}

L. F. CURTISs, Chairman

National Bureau of Standards
ROBLEY D. EVANB, Vice Chairman

Masbachusetts Institute of Tochnolosy

J. A. DeJUREN, Secretary

Westinghouse Electric Corporation

C. J. BORKOWSKI

Oak Ridge National Laboratory

ROBERT G. COCHRAN

Texas Agricultural and Mechanical

College

SAMUEL EPBTEIN

Callfornla Inutitute of Technology

U. FANO

National Bureau of standards

HERBERT COLDATEIN

Nuclear Development Corporation of

America
J. W. IRVINE, JR.

Massachusetts Inetitute of Technology

E. D. KLEMA

Northwestern University

W. WAYNE MEINKE

University of Michigan

J. J. NICKSON

Memorial Houpital, New York

ROBERT L. PLATZMAN

Laboratoire de Chimie Physique

D. M. VAN PATTER

Bartol Research Foundation

\section{LIAISON MEMBERS}

PAUL C. AIBERSOLD

Atomic Enerty Commlasion

J. HOW ARD MOMILLEN

National Bcience Foundation
CHARLES K. REED

U. 8. Air Force

WILLIAM E. WRIGHT

Office of Naval Research

\section{SUBCOMMITTEE ON RADIOCHEMISTRY}

W. WAYNE MEINKE, Chatrman

Univerelty of Michigan

GREGORY R. CHOPPIN

Florida 8tate University

GEORGE A. COWAN

Los Alamos sclentific Laboratory

ARTHUR W. FAIRHALL

Yniversity of Washington

JEROME HUDIS

Brookharen National Laboratory

EARL HYDE

University of California (Berkeley)

\section{HAROLD KTRBY}

Mound Laboratory

GEORGE LEDDICOTTE

Oak Ridge National Laboratory

JULIAN NIELGEN

Hanford Laboratories

ELLIB P. BTEINBERG

Arçonne National Laboratory

PETER C. BTEVENSON

University of Callfornia (Livermore)

LEO YAFFE

McGill University

\section{CONSULTANTS}

NATHAN BALLOU

Naval Radiological DefenBe Laboratory

\section{JAMES DEVOE}

University of Michigan 


\section{DISCLAIMER}

This report was prepared as an account of work sponsored by an agency of the United States Government. Neither the United States Government nor any agency Thereof, nor any of their employees, makes any warranty, express or implied, or assumes any legal liability or responsibility for the accuracy, completeness, or usefulness of any information, apparatus, product, or process disclosed, or represents that its use would not infringe privately owned rights. Reference herein to any specific commercial product, process, or service by trade name, trademark, manufacturer, or otherwise does not necessarily constitute or imply its endorsement, recommendation, or favoring by the United States Government or any agency thereof. The views and opinions of authors expressed herein do not necessarily state or reflect those of the United States Government or any agency thereof. 


\section{DISCLAIMER}

Portions of this document may be illegible in electronic image products. Images are produced from the best available original document. 


\title{
The Radiochemistry of the Transcurium Elements
}

\author{
G. H. HIGGINS \\ Lawrence Radiation Laboratory \\ University of California \\ Livermore, California
}

October 25, 1960

Subcommittee on Radiochemistry

National Academy of Sciences-National Research Council 



\section{FOREWORD}

The subcommittee on Radiochemistry is one of a number of subcommittees working under the Committee on Nuclear Sclence within the National Academy of Sclences - National Research Council. Its members represent government, industrial, and university laboratories in the areas of nuclear chemistry and analytical chemistry

The Subcommittee has concerned 1 tself with those areas of nuclear science which involve the chemist, such as the collection and distribution of radiochemical procedures, the establishment of specifications for radiochemically pure reagents, avallability of cyclotron time for service irradiations, the place of radiochemistry in the undergraduate college program, etc.

This serles of monographs has grown out of the need for up-to-date compllations of radiochemical information and procedures. The subcommittee has endeavored to present a serles which will be of maximum use to the working scient1st and which contains the latest avallable information. Each monograph collects in one volume the pertinent information required for radiochemical work with an individual element or a group of closely related elements.

An expert in the radiochemistry of the particular element has written the monograph, following a standard format developed by the subcommittee. The Atomic Energy Commission has sponsored the printing of the series.

The Subcommittee is confldent these publications will be useful not only to the radiochemist but also to the research worker in other flelds such as physics, biochemistry or medicine who wishes to use radiochemical techniques to solve a specific problem. 


\section{INTRODUCTION}

This volume which deals with the radiochemistry of the transcurium elements is one of a series of monographs on radiochemistry of the elements. There is included a review of the nuclear and chemical features of particular interest to the radiochemist, a discussion of problems of dissolution of a sample and counting techniques, and finally, a collection of radiochemical procedures for the element as found in the literature.

The series of monographs will cover all elements for which radiochemical procedures are pertinent. Plans include revision of the monograph periodically as new techniques and procedures warrant. The reader is therefore encouraged to call to the attention of the author any published or unpublished material on the radiochemistry of the transcurium elements which might be included in a revised version of the monograph. 


\section{CONTENTS}

I. General Comments . $\quad$. $\quad$. $\quad$. $\quad$. 1

II. General Reviews of the Chemistry of

the Transcurium Elements . . . . . 2

III. Table of Isotopes of the

Transcurium Elements

IV. Review of Features of Transcurium Element

Chemistry Most Interesting to Radiochemists

A. Coprecipitation and

Precipitation Chemistry

B. Complex Ions and

Chelate Formations

C. Extraction Behavior . . . . 6

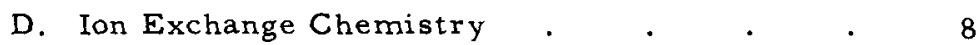

1. Separations of the actinides and lanthanides

2. Separations of the transcurium elements from each other

V. Dissolution of Samples and Special

Problems Related to Handling the

Transcurium Elements

VI. Counting Procedures and

Source Preparations $\quad . \quad$. $\quad . \quad$. 20

VII. Specific Separation Procedures . . . 23 


\title{
The Radiochemistry of the Transcurium Elements
}

\author{
G. H. HIGGINS \\ Lawrence Radiation Laboratory \\ University of California \\ Livermore, California
}

\section{GENERAL COMMENTS}

The transcurium element group is composed of berkelium (Bk), atomic number 97; californium (Cf), number 98; einsteinium (Es), number 99; fermium (Fm), number 100; mendelevium (Md), number 101; and nobelium (No), number 102 .

These elements are all synthetic; that is, they are all usually produced by multiple neutron capture or charged particle reactions on isotopes of elements of lower atomic number. Their discovery and production is described by Thompson. ${ }^{1}$ With the inclusion of the as yet undiscovered element 103 they compose the second half of the actinide series in which the $5 f$ electron shell is being completed. Their chemistry is extraordinarily similar to that of the lanthanides or rare earths. Excepting Bk (and possibly No), they exist solely as tripositive ions in aqueous solutions. Bk can be oxidized to the +4 state under conditions equivalent to those required for oxidation of $\mathrm{Ce}^{+3}$ to $\mathrm{Ce}^{+4}(\approx 1.6 \mathrm{v})$.

The chemical properties of any one of these elements are quite similar to those of the rest, so it is appropriate to speak of many of their chemical properties in collective terms. The radiochemical procedures can usually be divided into three parts: 
1. The isolation of a tripositive lanthanide-actinide fraction.

2. Separation of the tripositive actinides from the lanthanides.

3. Separation of the actinides from each other.

The transcurium actinides have characteristic a decay energies (note that the light $\mathrm{Pb}-\mathrm{B} 1$ isotopes may be confused with some transcurium nuclides) and short spontaneous fission half-lives. Because of these properties they can be identified and measured without being entirely separated from fission products, and hence some of the procedures do not provide for complete purifications.

The lightest transcurium element, $B k$, is five atomic numbers beyond the last abundantly occurring natural element, uranium. The longer-lived 1sotopes of Bk are several mass numbers more than 238, so even this most easily produced transcurium element is several transmutation generations away from natural occurrence. Therefore these elements have not yet been avalable for study in larger than microgram quantities. Cunningham ${ }^{2}$ and Thompson and Muga ${ }^{3}$ have reported the magnetic susceptibilities of the tripositive $B k$ and $C f$ ions as well as the solution absorption spectra in the range from about 5300 to $8700 \mathrm{~A}$. Neither ion is strongly colored although $\mathrm{Cf}^{+3}$ displays two weak absorption peaks at 7800 and $8300 \mathrm{~A}$. These studies are remarkable in that they were performed on submicrogram quantities of $B k$ and $C f$. No such work has been possible on Es, Fm, Md, or No, and in fact almost no chemical studies, even at tracer levels, have been possible on $\mathrm{Md}$ and No because the half-lives of the observed isotopes are so short. It is clear that there is very little information about these elements except what is derived from tracer studies and comparisons with the chemistry of the lanthanides.

\section{GENERAL REVIEWS OF THE CHEMISTRY OF THE TRANSCURIUM}

\section{ELEMENTS}

General reviews of the chemistry of the transcurium elements can be found in the following books and articles: 
G. T. Seaborg, "The Transuranium Elements," Addison-Wesley Publishing Co., Inc., Reading, Mass., 1958. [Ref.4.]

J. K. Katz and G. T. Seaborg, "Chemistry of the Actinide Elements," Methuen and Co., Ltd., London, 1957. [Ref. 5.]

S. G. Thompson, B. G. Harvey, G. R. Choppin, and G. T. Seaborg, J. Am. Chem. Soc. 76, 6229 (1954). [Ref.6.]

B. B. Cunningham, J. Chem. Educ. 36 (January, 1959). [Ref.2.]

S. G. Thompson and M. Louis Muga, "Methods of Production and Research on Transcurium Elements," Proc. U. N. Intern. Conf. Peaceful Uses Atomic Energy, 2nd, Geneva, 1958, 15/P/825. [Ref.3.]

\section{TABLE OF ISOTOPES OF THE TRANSCURIUM ELEMENTS}

Nuclide

$$
97^{\mathrm{Bk}^{243}}
$$

$\mathrm{Bk}^{244}$

$\mathrm{Bk}^{245}$

$\mathrm{Bk}^{246}$

$\mathrm{Bk}^{247}$

$\mathrm{Bk}^{248}$

$\mathrm{Bk}^{249}$

$\mathrm{Bk}^{250}$

${ }_{98} \mathrm{Cf}^{244}$

$C f^{245}$

Cf $f^{246}$

$\mathrm{Cf}^{247}$

Cf ${ }^{248}$

${ }_{98} \mathrm{Cf}^{249}$

$C f^{250}$

Cf 251

$\mathrm{Cf}^{252}$

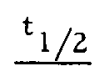

$$
4.5 \mathrm{~h}
$$

$4.4 \mathrm{~h}$

4. $98 \mathrm{~d}$

1. $8 \mathrm{~d}$

$\approx 10^{4} \mathrm{y}$

$16 \mathrm{~h}$

$314 \mathrm{~d}$

3. $13 \mathrm{~h}$

$25 \mathrm{~m}$

$44 \mathrm{~m}$

$35.7 \mathrm{~h}$

$2.5 \mathrm{~h}$

$350 \mathrm{~d}$

$360 \mathrm{y}$

$10.9 \mathrm{y}$

$\approx 800 \mathrm{y}$

$2.2 \mathrm{y}$

\section{Mode of Decay}

EC, $99+\% ; a, 0.15 \%$

EC, $99+\% ; a, 6 \times 10^{-3} \%$

EC, $99+\% ; a, 0.11 \%$

EC

a

$\boldsymbol{\beta}, 70 \% ; \mathrm{EC}, 30 \%$

$\beta^{-}, 99+\% ;$ a $2.2 \times 10^{-3} \% ; S F, 6 \times 10^{-6} \%$

$\beta^{-}$

a

EC, $70 \% ; a, 30 \%$

a; SF, $2 \times 10^{-4} \%$

EC

a; $S F>1.5 \times 10^{-2} \%$

a; SF, $4 \times 10^{-4} \%$

a; $\mathrm{SF} \approx 0.15 \%$

a

a, $97 \% ; \mathrm{SF}, 3 \%$ 
III. TABLE OF ISOTOPES OF THE TRANSCURIUM ELEMENTS (Contd.)

Nuclide

$$
\text { C. } f^{253}
$$

$\mathrm{Cf}^{254}$

$99^{E s^{246}}$

$\mathrm{Es}^{247}$

$\operatorname{Es}^{248}$

Es 249

$\mathrm{Es}^{250}$

$\mathrm{Es}^{251}$

$\mathrm{Es}^{252}$

Es ${ }^{253}$

$\mathrm{Es}^{254}$

$\mathrm{Es}^{255}$

Es $^{256}$

${ }_{100} \mathrm{Fm}^{248}$

Fm $^{249}$

$\mathrm{Fm}^{250}$

$\mathrm{Fm}^{251}$

$\mathrm{Fm}^{252}$

$\mathrm{Fm}^{253}$

${ }_{100} \mathrm{Fm}^{254}$

$\mathrm{Fm}^{255}$

$\mathrm{Fm}^{256}$

$10 \mathrm{l}^{255}$

$\mathrm{Md}^{256}$

$102^{\mathrm{No}}$
${ }^{t} 1 / 2$

$17 \mathrm{~d}$

$56 \mathrm{~d}$

7. $3 \mathrm{~m}$

$25 \mathrm{~m}$

$2 \mathrm{~h}$

$8 \mathrm{~h}$

$1.5 \mathrm{~d}$

$\approx 140 \mathrm{~d}$

$20.03 \mathrm{~d}$

$480 \mathrm{~d}$

$37 \mathrm{~h}$

$24 \mathrm{~d}$

short

$0.6 \mathrm{~m}$

$150 \mathrm{~s}$

$30 \mathrm{~m}$

$7 \mathrm{~h}$

$22.7 \mathrm{~h}$

$\approx 3.0 \mathrm{~d}$

$3.24 \mathrm{~h}$

$21.5 \mathrm{~h}$

3-4h

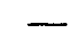

$\approx 30 \mathrm{~m}$

$\approx 10 \mathrm{~s}$

\section{Mode of Decay}

$\beta^{-}$

$\mathrm{SF} \approx 100 \%$

a, EC

a

EC, $99+\% ; a, 0.3 \%$

EC, $99+\% ; a, 0.13 \%$

EC

EC, $99+\% ; a, 0.53 \%$

a

a) SF, $8 \times 10^{-6} \%$

a; no $\beta^{-}$

$\beta^{-}, 99+\% ;$ EC $\approx 0.1 \%$

$\beta^{-}$

$\beta^{-}$

a

a

a, EC

$\mathrm{EC} \approx 99 \% ; a \approx 1 \%$

a; $\mathrm{SF}<4 \times 10^{-2} \%$

EC, $89 \% ; a, 11 \%$

a) SF, $5.50 \times 10^{-2} \%$

a; $\mathrm{SF}<4.5 \times 10^{-3} \%$

$\mathrm{SF} \approx 100 \%$

$a+$ ?

EC

$\mathbf{a}+$ ? 
III. TABLE OF ISOTOPES OF THE TRANSCURIUM ELEMENTS (Contd.)

$\begin{array}{lll}\text { Nuclide } & \frac{t_{1 / 2}}{25} & \text { Mode of Decay } \\ \text { No } & 354 & a+? \\ 103-\begin{array}{c}256 \\ \text { identative }\end{array} & 0.25 \mathrm{~s} & a+?\end{array}$

Abbreviations in the table above are as follows:

$s=$ seconds, $\mathrm{m}=$ minutes, $\mathrm{h}=$ hours, $\mathrm{d}=$ days, $\mathrm{y}=$ years,

$\mathrm{EC}=$ electron capture, $a=a$ particle emission, $\beta^{-}=$negatron

emission, $S F=$ spontaneous fission decay.

A more complete description of most of these nuclides can be found in the compilation by Strominger, Hollander, and Seaborg in Reviews of Modern Physics, Vol. 30, No. 2, Part II, pp. 585-904. The a particle energies, decay schemes, and genetic relationships are tabulated.

\section{REVIEW OF FEATURES OF TRANSCURIUM ELEMENT CHEMISTRY MOST INTERESTING TO RADIOCHEMISTS}

\section{IV.A. Coprecipitation and Precipitation Chemistry}

The tripositive actinides display such marked similarity to the lanthanides that one of the latter (usually $\mathrm{Ce}$ or La) is ordinarily used as a carrier during precipitation steps. They all form insoluble fluorides from strong $(\approx 3-5 \underline{M})$ acid, oxalates from less strong acids $(\approx 1-2 \underline{M})$, phosphates in slightly acidic solutions $(\approx 0.1 M)$, and hydroxides or hydrated oxides in basic solutions. These hydrated oxides are insoluble in dilute carbonates, but they readily dissolve in excess $(40 \%)$ carbonate or many of the complexing anions of organic acids such as citrate.

While there are several other ions which coprecipitate as insoluble oxyfluorides at lower acid concentrations, the precipitation of fluorides

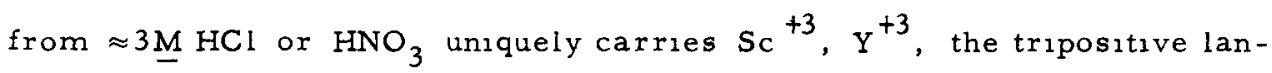
thanides and actinides, thorium, and the alkaline earths. The alkaline earth 
group is left in solution when the remainder of these elements are precipitated as hydrated oxıdes from carbonate-free solutions. Holdback Sr ${ }^{++}$ enhances the separation achieved with any single precipitation step.

Of course, the transcurium elements do not carry appreciably on acid sulfides, lead chromate, barium sulfate, or silver chloride.

$\mathrm{Bk}^{+4}$ coprecipitates with zirconium phosphate, zirconium lodate and ceric lodate, and insoluble hydroxides. 7

\section{IV.B. Complex Ions and Chelate Formations}

The order of the complexing power of different anions is fluoride > chloride > nitrate > perchlorate for mononegative anzons, and carbonate > oxalate > sulfate for dinegative anions. The complex/chelate formation is of utmost importance in ion exchange separations since the +3 lons are so strongly adsorbed on cation resin that special measures are required for their rapid elution. Complex ions are formed with organic substances, and citrate, tartrate, lactate, a-hydroxysobutyrate, EDTA, TTA, acetate, and throc yanate are known to form moderately strong complexes. For instance, the dissociation constant of the EDTA complex of Cf is listed as $10^{-19.09 \pm 0.2}$ by Fuger. 8

\section{IV.C. Extraction Behavior}

The only rapid extraction separation for the transcurium elements involves the extraction of $\mathrm{Bk}^{+4}$ away from Bk${ }^{+3}, \mathrm{Cm}^{+3}$, and $\mathrm{Cf}^{+3}$ into di(2-ethylhexyl) orthophosphoric acid-heptane from $\mathrm{HNO}_{3}$ solutions. The ratio of extraction coefficients for the +4 state is more than $10^{6}$ times that for the +3 state. 9 Procedure 6 (Section VII of this report) 1s based on this extraction.

Cf, Es, Fm, and $\mathrm{Cm}$ can be separated from each other and from the lanthanides with appropriate extractions into di(2-ethylhexyl) phosphoric acid, 2 -ethylhexyl phosphoric acid,or diphenyl phosphoric acid from aqueous $\mathrm{HCl}$ solutions. ${ }^{10}$ These extractions are effective with macro concentrations of Cf. ${ }^{11}$ 
The extractions of the lanthanides and actinides into tri-n-butyl phosphate are discussed by Best et al. ${ }^{12}$ and a purification of Bk with this reagent is described by Hulet. ${ }^{13}$

Magnussen et al. ${ }^{14}$ have reported the extraction coefficients of several of the transcurium elements from 0.1M ammonium chloroacetate buffer into TTA-toluene solutions. The data fit the equation

$$
K=\frac{E\left(\mathrm{H}^{+}\right)^{3}}{(\mathrm{HT})^{3}\left(\mathrm{f}_{\mathrm{HT}}\right)^{3}},
$$

where $E$ is the extraction coefficient, $H T$ is the $T T A$ concentration in the organic layer, and $f_{H T}$ is the TTA activity coefficient in the organic phases given by $\mathrm{f}_{\mathrm{HT}}=1-0.24(\mathrm{HT})^{0.48}$. The data are listed in Table $\mathrm{I}$, corrected to benzene solvent by Poskanzer and Foreman ${ }^{15}$ who subtracted $0.2 \mathrm{pH}$ unit from the $\mathrm{pH}_{50}$ value obtained in toluene and recalculated $\mathrm{K}$.

Table I. Extraction coefficients (K) of the transcurium elements for extraction from 0. IM ammonium chloroacetate into TTA-toluene solutions.

\begin{tabular}{crc}
\hline Ion & $\mathrm{K}$ & $\mathrm{pH}$ for $50 \%$ Extraction (Benzene) \\
$\mathrm{Bk}^{+3}$ & $\approx 1.5 \times 10^{-7}$ & 3.0 \\
$\mathrm{Cf}^{+3}$ & $8 \times 10^{-8}$ & 3.1 \\
$\mathrm{E}^{+3}$ & $6 \times 10^{-8}$ & 3.1 \\
$\mathrm{Fm}^{+3}$ & $8 \times 10^{-8}$ & 3.1 \\
\hline
\end{tabular}

The lanthanides extract under nearly the same conditions, 1.e., $\mathrm{pH}_{50}$ for La is $\approx 4.0$ and $\mathrm{pH}_{50}$ for $\mathrm{Lu} 1 \mathrm{~s} \approx 3.0$, so lanthanide-actinide separations are not readily feasible. Group separations from ions of the alkaline earth group, the $+4 \mathrm{Zx}-\mathrm{Hf}$ family, and the oxygenated ions can be performed by pre-extracting $\mathrm{Zr}, \mathrm{Hf}, \mathrm{Pa}, \mathrm{Np}, \mathrm{Pu}$, etc. from a solution adjusted to $\mathrm{pH} 2$, discarding the organic phase, then adjusting the $\mathrm{pH}$ to 4.5 and extracting the lanthanides and actinides. This step has not been reported in any of the currently used procedures. 


\section{IV.D. Ion Exchange Chemistry}

The great similarity between the various transcurium elements has intensified interest in and work on their ion exchange behavior. With the exception of No, the transcurium elements have been identıfied by their relative elution positions from cation exchange resin. While separation procedures have been devised which do not make use of ron exchange operations, they are not presently in general use.

In order to compare data from various sources, the ion-exchangecolumn eluate volumes have been reduced to units of "free column volumes." This volume, abbreviated FCV, is characteristic of a particular resin bed loading and can be derived for any column by finding the elution position of unadsorbed materials such as organic dyes, etc. The FCV is about $55 \%$ of the volume of the column bore.

IV.D. 1 Separations of the actinides and lanthanides The chloride and thiocyanate complexes of the actinides are stronger than the corresponding complexes of the lanthanides, When mixtures of lanthanides and actinides are eluted from strong base cation resins such as Dowex-50 or Zeo-Carb 225 with $12 \mathrm{M} \mathrm{HCl}$ or $2 \mathrm{MNH}_{4} \mathrm{CNS}$, the actinides are eluted before the lanthanides and group separations are obtained. Figure lindicates the relative elution positions from Dowex-50 AG with $20 \%$ ethyl alcohol saturated with HCl gas at $20^{\circ} \mathrm{C} .6,16$ Similar separations are obtained with the same eluant from Zeo-Carb 225 resin. Figure 2 shows the relative elution positions from Dowex-50 using 1.8 $\mathrm{M} \mathrm{NH}_{4}$ CNS eluate. ${ }^{17}$

The complexes of the actinides in very strong complexing agents such as $13 \underline{\mathrm{M} \mathrm{HCl}}, 10 \underline{\mathrm{M} \mathrm{LiCl}}$, and $2 \underline{\mathrm{M}} \mathrm{NH}_{4} \mathrm{CNS}$ are such that anionic species are formed. Similar anionic species of the lanthanides are not as probable under the same conditions, so group separations are possible using these complexing agents and anion exchange resin. 18

Figure 3 shows the relative elution positions of the actinides from Dowex-1 anion resin with $13 \underline{M} \mathrm{HCl},{ }^{6}$ Similar or better separatons have 



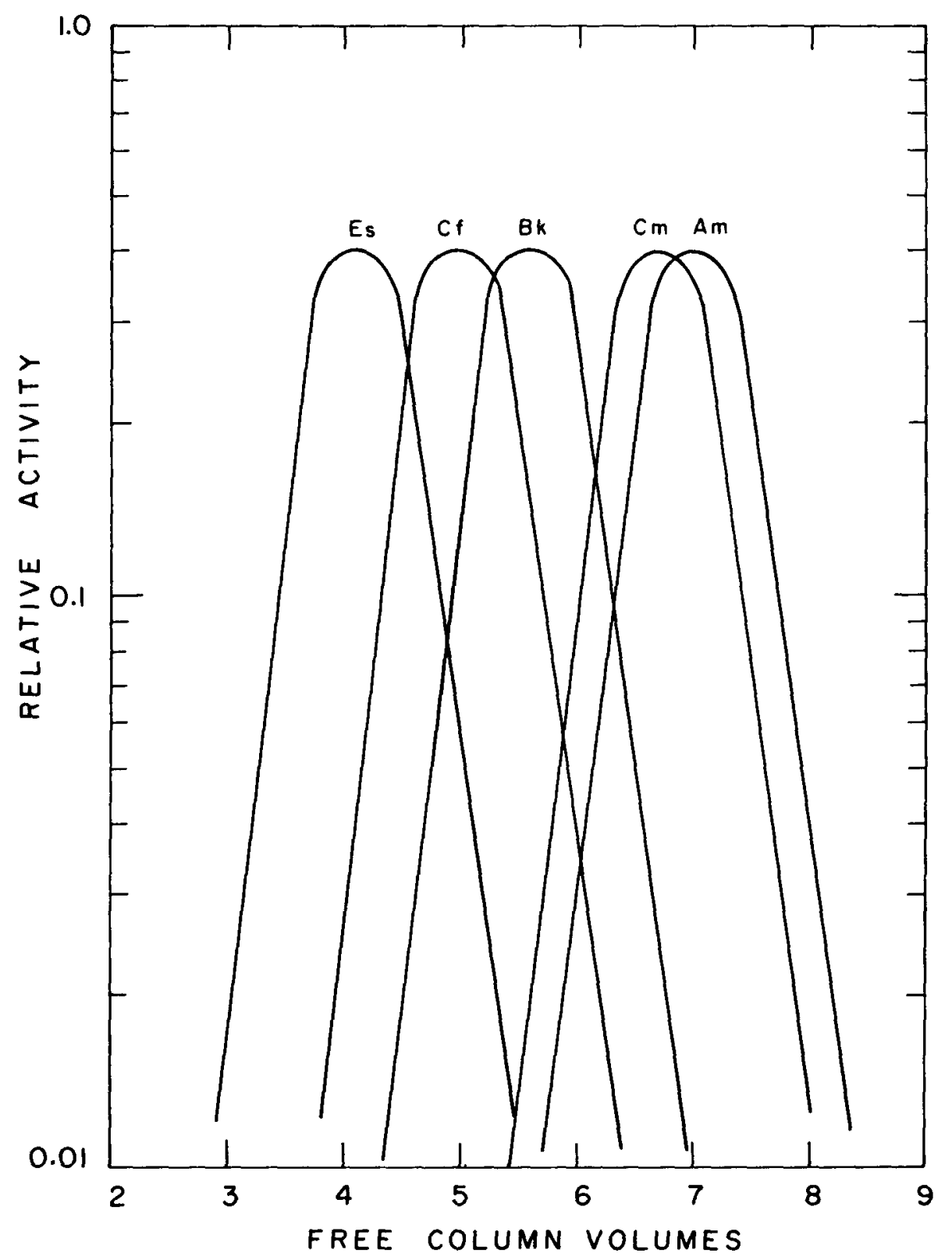

Fig. 2. Relative elution positions of the transplutonium actinides from Dowex-50 with $1.8 \mathrm{M}$ ammonium thiocyanate at $87^{\circ} \mathrm{C}$. 


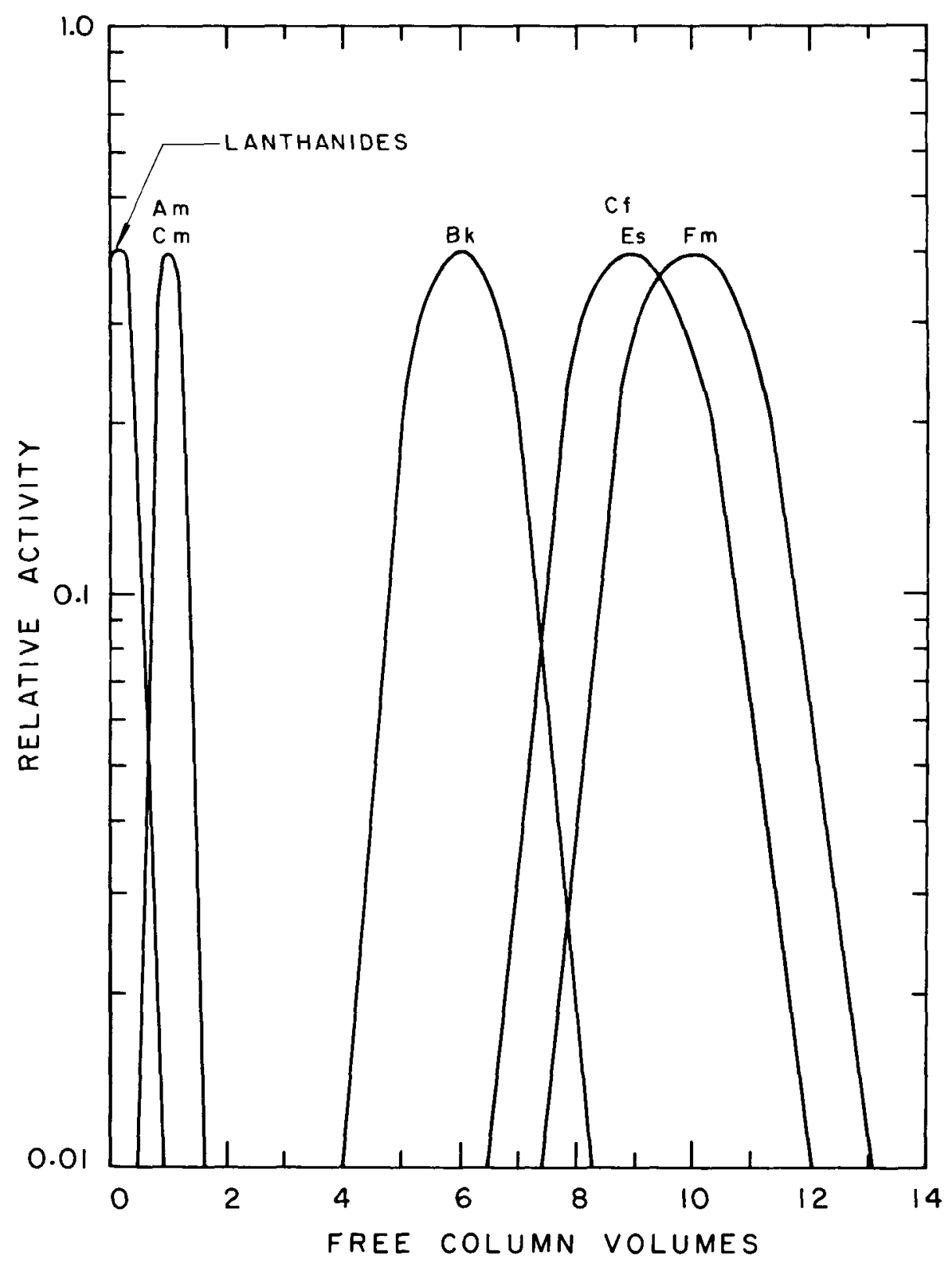

Fig. 3. Relative elution positions of the lanthanides and transplutonium actinides from Dowex-1 with $13 \mathrm{M} \mathrm{HCl}$ at room temperature. 


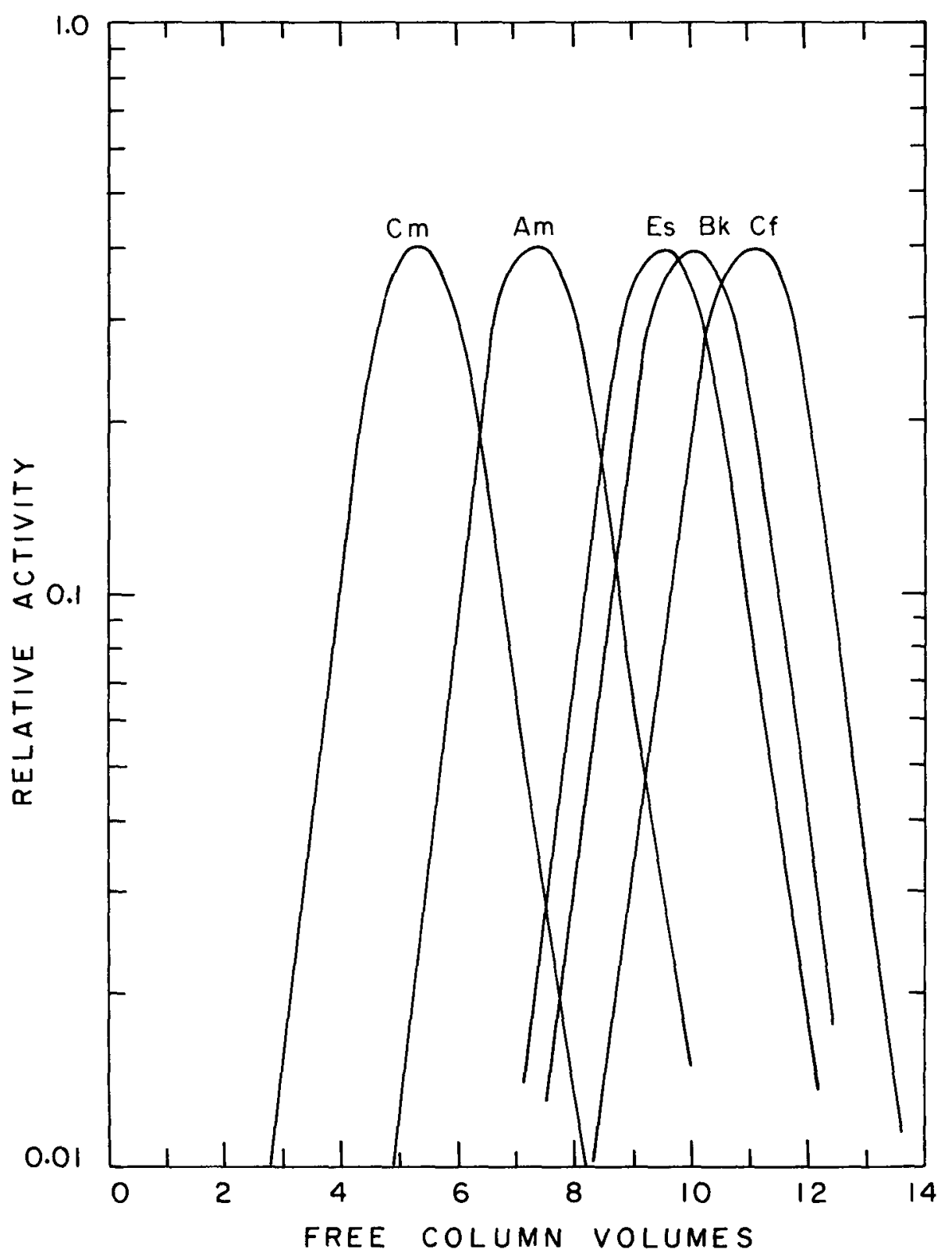

Fig. 4. Relative elution positions of the transplutonium actinides from Dowex-1 with $2.0 \underline{\mathrm{M}}$ ammonium thiocyanate at $87^{\circ} \mathrm{C}$. 
been reported using the same eluant and Amberlite IRA-400. ${ }^{19}$ Figure 4 shows the relative elution positions from the same resin using $2 \underline{\mathrm{M}} \mathrm{NH}_{4} \mathrm{CNS}$. Lithium chloride solutions of about $10 \underline{M}$ give adsorptions and elutions equivalent to $13 \underline{M} \mathrm{HCl}$.

When the transcurium actinides are eluted from cation resins like Dowex-50 AG(4\% cross-linked) with $0.1 \underline{M}$ to $6 \underline{M ~ H C l, ~ v e r y ~ l i t t l e ~ s e p a r a t i o n ~}$ between the actinides and lanthanides is obtained, but separations from most other cations can be effected. Procedure 7 (Section VII of this report) by Phillips and Gatti 20 uses a "cleanup" column operated primarily to remove impurities of $\mathrm{Ca}, \mathrm{Fe}$, and $\mathrm{Al}$. Columns operated at $87^{\circ} \mathrm{C}$ are assembled as shown in Fig. 5. Trichloroethylene is boiled and its vapor is conducted

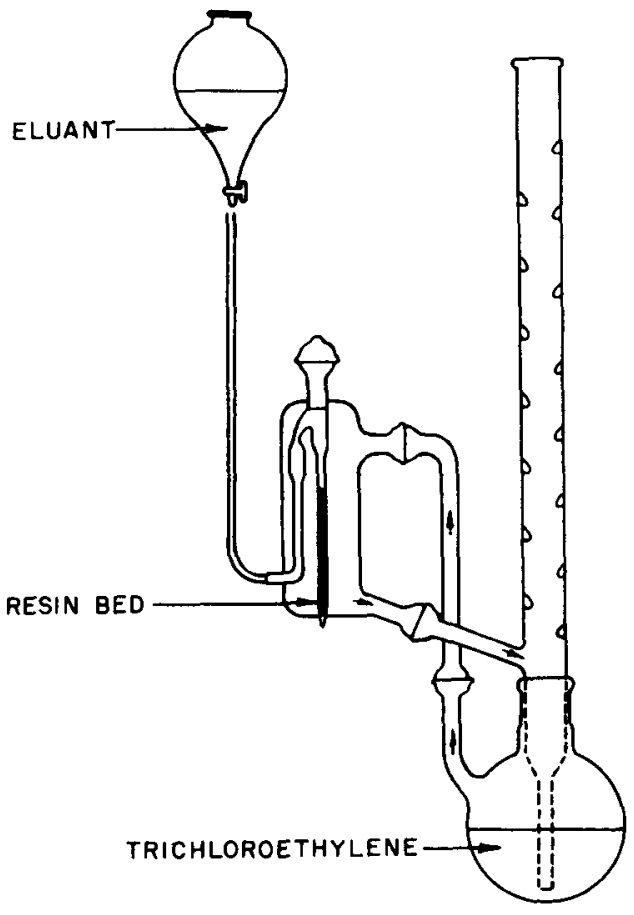

Fig. 5. Column apparatus for elutions at $87^{\circ} \mathrm{C}$. Trichloroethylene is boiled in the flask, the vapors conducted through the column jacket around the resin bed, and the condensed vapor returned to the flask.

around the column into a condenser and back to the boiling flask, thus providing heat exchange at $87^{\circ} \mathrm{C}$. Higher column temperatures are less practical because of the formation of vapor bubbles in the solutions and resin bed; however, with adequate care, temperatures to $100^{\circ} \mathrm{C}$ can be used. 
IV.D. 2 Separations of the transcurium elements from each other. While separations of the transcurium elements from each other are obtained with relatively concentrated $\mathrm{HCl}$ and $\mathrm{NH}_{4} \mathrm{CNS}$, no element is separated cleanly from its neighbor.

The most convenient and frequently used method for separation of these elements from each other has been to elute them from cation resin with chelatıng organic acid anıons. Several acid anions including those of citric, glycolic, tartaric, lactic, and a-hydroxysobutyric acid have been used successfully as eluants. 21 While some advantage is obtained in separation factors if a-hydroxysobutyrate is used, the general features of the elution are the same with any of the eluants. Figure 6 is a typical elution curve of the actınides from Dowex-50 ( $12 \%$ cross-linked) with ammonium a-hydroxyisobutyrate Similar elutions are reported at room temperature from the same resin $(4 \% \text { cross-linked) })^{16}$ and at $77^{\circ} \mathrm{C}$ from Zeo-Carb $225 .^{22}$

Table II indicates the elution positions of the actinides and lanthanides from cation resin with a-hydroxyisobutyric acid The data are normalized to $\mathrm{Cm}=1.00$. Data have been summarized from Choppin et al, 21 Smith and Hoffman, ${ }^{16}$ and Milsted and Beadle. 22

Since the elution position of a particular element depends on the competition between the resin and a solution phase chelate, the position can be varied at will by adjusting the parameters that determine the chelate concentration. These are the $\mathrm{pH}$ of the solution of weak acids which form chelating anions, and the total acid concentration. Figure 7 shows the effect of varying the $\mathrm{pH}$ of solutions of ammonium a-hydroxyisobutyric acid The effect of a change of a-hydroxyisobutyric acid concentration can be calculated by assuming $K_{d}$ will be unchanged when the anion concentration is the same and the ionization constant of the acid is $1.1 \times 10^{-4}$.

The spacing between the heavier members of the series, Md and Fm, is much less than the spacing between $C f$ and $B k$ for constant $p H$ and concentration of eluant. Although nearly equal spacing has been attained for rare-earth separations in columns utılizing continuously variable eluants, ${ }^{23}$ 


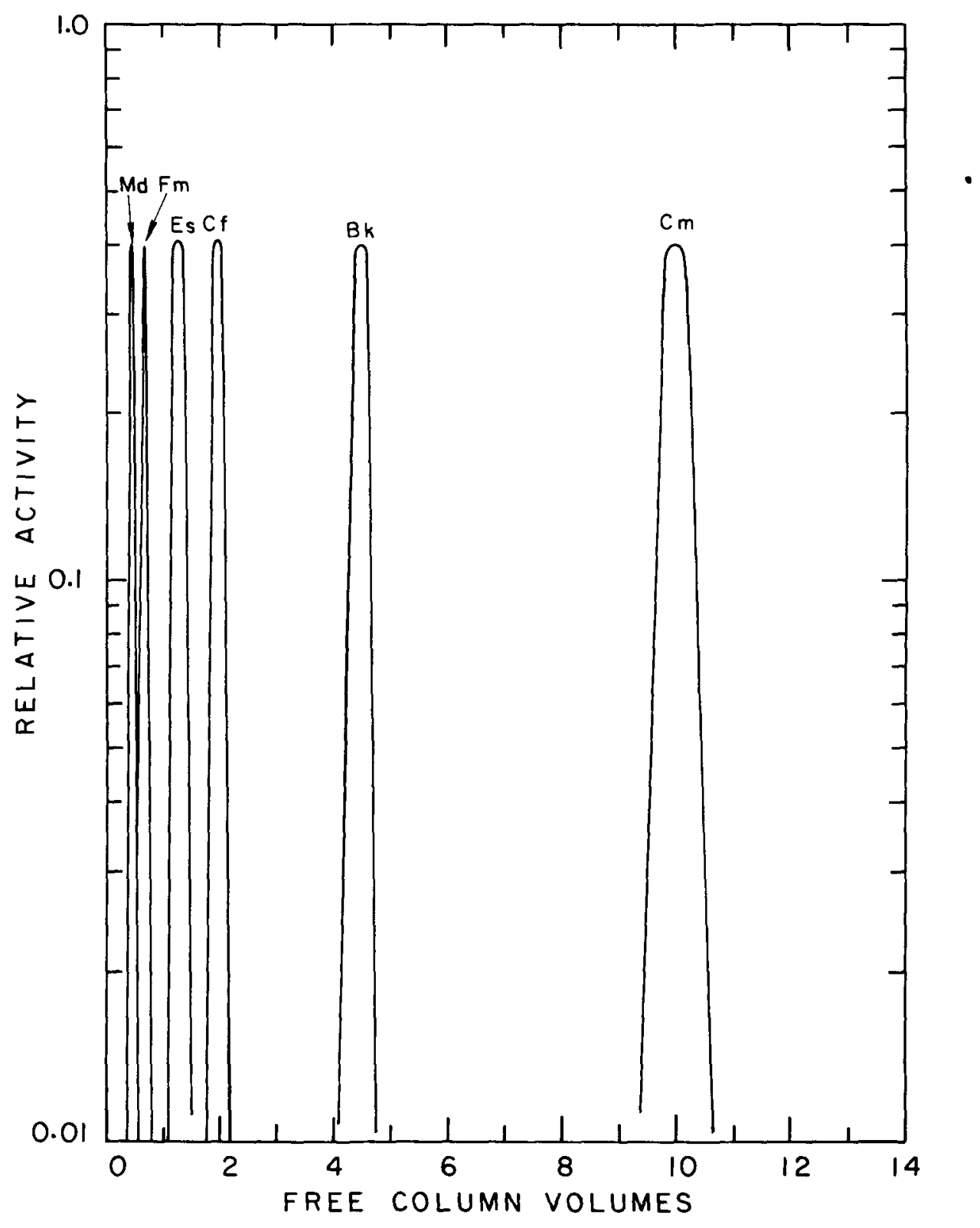

Fig. 6. Relative elution positions of curium and the transcurium actinides from Dowex-50 12\% cross-linked resin with $\mathrm{pH} 4.2$ ammonium a-hydroxyisobutyrate at $87^{\circ} \mathrm{C}$. 
Table II. Elution positions of actinides and lanthanides from cation exchange resin with a-hydroxyisobutyric acid.

\begin{tabular}{|c|c|c|c|}
\hline Element & $\begin{array}{c}\text { Dowex-50 } 4 \% \text { at } \\
25^{\circ} \mathrm{C}\end{array}$ & $\begin{array}{c}\text { Zeo-Carb } 225 \text { at } \\
77^{\circ} \mathrm{C}\end{array}$ & $\begin{array}{c}\text { Dowex }-50 \quad 12 \% \text { at } \\
87^{\circ} \mathrm{C}\end{array}$ \\
\hline $\mathrm{Md}$ & -- & - & 0.050 \\
\hline $\mathrm{Fm}$ & -- & -- & 0.069 \\
\hline $\mathrm{Es}$ & 0.13 & -- & 0.13 \\
\hline $\mathrm{Cf}$ & 0.19 & 0.21 & 0.20 \\
\hline $\mathrm{Bk}$ & 0.37 & -. & 0.45 \\
\hline $\mathrm{Cm}$ & 1.00 & 1.00 & 1.00 \\
\hline $\mathrm{Am}$ & 1.39 & 1.38 & 1.4 \\
\hline $\mathrm{Lu}$ & 0.11 & - & 0.015 \\
\hline $\mathrm{Yb}$ & 0.016 & $-\cdots$ & 0.020 \\
\hline $\mathrm{Tm}$ & 0.22 & $\cdots$ & 0.026 \\
\hline $\operatorname{Er}$ & -- & -- & 0.037 \\
\hline Ho & 0.039 & -- & 0.055 \\
\hline $\mathrm{Y}$ & 0.069 & -- & 0.06 \\
\hline Dy & 0.076 & -- & 0.078 \\
\hline $\mathrm{Tb}$ & 0.14 & -- & 0.14 \\
\hline $\mathrm{Gd}$ & 0.22 & -- & 0.28 \\
\hline $\mathrm{Eu}$ & 0.34 & $\cdots$ & 0.39 \\
\hline $\mathrm{Sm}$ & 0.7 & -- & 0.71 \\
\hline $\mathrm{Pm}$ & 1.1 & $\cdots$ & 1.2 \\
\hline $\mathrm{Nd}$ & 2.3 & -- & 2.1 \\
\hline La & -- & -- & -. \\
\hline $\mathrm{Ce}$ & 3.4 & $\ldots$ & 3.5 \\
\hline
\end{tabular}

there are no reports that this has been accomplished with the transcurium elements.

The flow rate at which a column is operated affects the apparent width of the elution peaks. Figure 8 shows the effect for Dowex-50 $12 \%$ resin, graded to settle at 0.5 to $0.25 \mathrm{~cm} / \mathrm{min}$ in water, when the eluate is $0.4 \mathrm{M}$ lactic acid and the column is operated at $87^{\circ} \mathrm{C}$. The curve is displaced toward greater half-widths at the same flow rate when coarser resin is used. A limiting half-width of about 5 or $6 \%$ is found with the finest resin and slowest flow rates. 


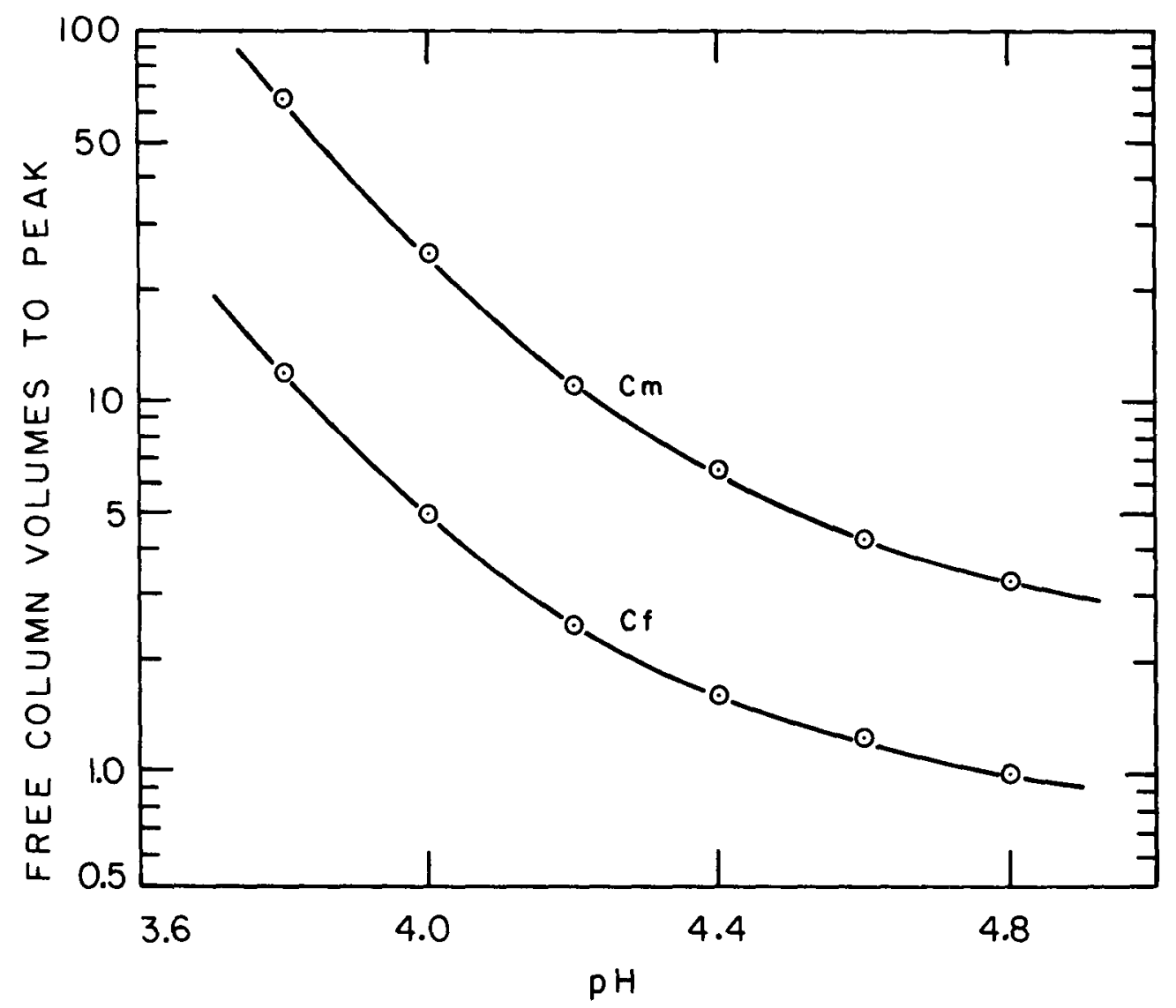

Fig. 7. The peak position of $\mathrm{Cf}$ and $\mathrm{Cm}$ as a function of $\mathrm{pH}$ for $0.4 \mathrm{M}$ ammonium a-hydroxyisobutyrate and Dowex $-50.12 \%$ cross-linked resin. The peak position of other lanthanides and actinides can be predicted from this curve and the table in the text. 


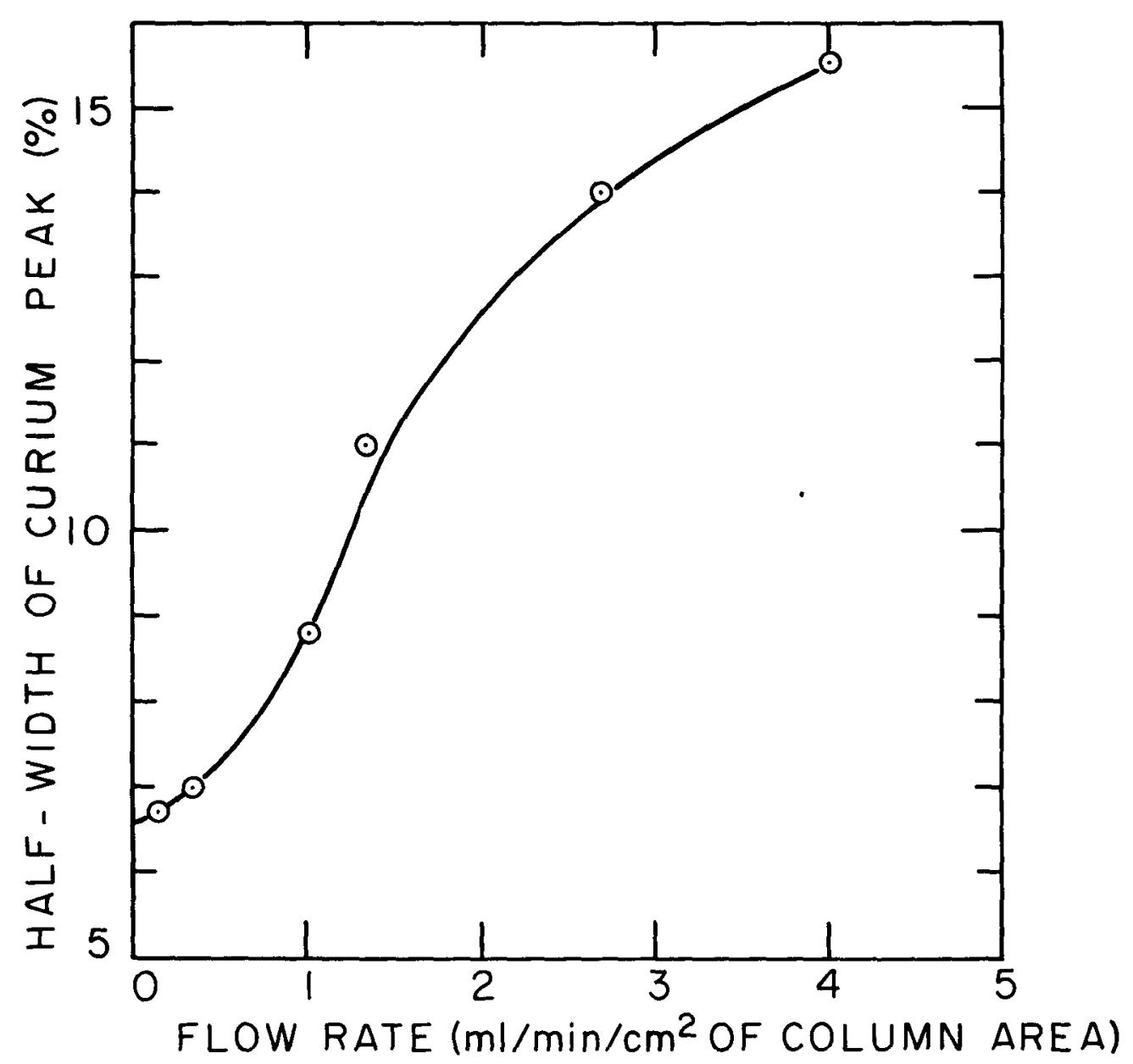

Fig. 8. Full width at half maximum (half-width) of the elution peak of curium from Dowex-50 $12 \%$ cross-linked resin with $0.4 \mathrm{M}$ ammonium lactate at $87^{\circ} \mathrm{C}$ on one particular column. Similar curves would be obtained with other eluants and other columns, but the resin particle size, temperature of operation, length-to-diameter ratio of the resin bed, technique, and the presence or absence of carriers or mass impurities all affect the absolute value of half-width at any flow rate.

\section{DISSOLUTION OF SAMPLES AND SPECIAL PROBLEMS RELATED TO} HANDLING THE TRANSCURIUM ELEMENTS

The transcurium elements are all unstable with respect to a particle emission. Spontaneous fission is also a disintegration mode so that considerable numbers of neutrons may be emitted by some samples and targets. These facts make the handling of microgram or larger quantities of some transcurium elements very difficult and potentially hazardous. Most chemical operations must be carried on in gloved boxes, and in many instances 
remote-control handling equipment is required even after the samples are free of fission product contamination For instance, 1 microgram of $C f^{252}$ emits $\approx 2 \times 10^{8}$ neutrons $/ \mathrm{min}$ and presents about a tolerance working dose of neutrons at a distance of 1 meter. Laboratories equipped to handle the transcurium elements should have a-particle and neutron survey meters as well as the usual $\beta-\gamma$ survey meters

The transcurium elements are produced in at least three different kinds of target. The neutron-deficient isotopes are produced by heavy-ion bombardments of uranium or plutonium by reactions such as

$$
{ }_{92} \mathrm{U}^{238}+{ }_{6} \mathrm{C}^{12} \longrightarrow{ }_{0} \mathrm{n}^{\mathrm{l}}+{ }_{98} \mathrm{Cf}^{246}
$$

in which the product atoms are collected on "recoll catchers" separate from the bombarded target material. The techniques and difficulties are discussed by Thompson and Muga ${ }^{3}$ and Ghiorso and Sikkeland. 24 Briefly, when the chemistry is done, the target or catcher foil is dissolved in the appropriate strong acid solution and the appropriate separations are performed When the transcurium elements are produced in this way no special handling equipment, such as glove boxes, may be needed although it may be needed for target preparation if transplutonium elements are bombarded. The target itself is seldom dissolved or handled when the recoil technique is used Since the recoil atoms retain positive charges when stopped in helium gas, they can be electrostatically collected as thin samples and sometimes their decay characteristics can be studied without chemistry, however, some of the $\mathrm{Pb}$ and $\mathrm{B} 1$ isotopes have similar a-decay half-lives and particle energies so that identification by a particle measurements alone may be unreliable. The experiments done by Ghiorso, Sikkeland, Walton, and Seaborg leading to the discovery of element 102 (nobelium) are classic in the sense that every advantage has been taken of these nonchemical separation techniques. If chemistry is done on such electrostatically collected material, the collector plates are simply washed with concentrated $\mathrm{HCl}$ and the transcurium elements are removed without dissolution of the plate. 
The second source of transcurium elements is the debris from thermonuclear explosions. Es and $F m$ were first discovered in filtered samples of the cloud produced by a multı-megaton thermonuclear explosion in which they had been produced by multiple neutron capture in $\mathrm{U}^{238}$. The filter was dissolved by repeatedly digestung it in concentrated $\mathrm{HNO}_{3}$ and finally destroying the last traces of organic material by fuming the residue in concentrated $\mathrm{HClO}_{4}$. The fuming perchloric acid was then diluted with more than 10 times its volume of $6 \mathrm{~N} \mathrm{HCl}$, and a separation procedure similar to Procedure 2 (Section VII) was performed on aliquots of this solution. The major massive impurities in such a solution are $\mathrm{Ca}, \mathrm{Fe}, \mathrm{Na}$, and Al. This kind of sample usually has so little radiation that special handling equipment is unnecessary

The last and most generally encountered source of the transcurium elements is uranium, plutonzum, americium, or curium that has been exposed to large integrated neutron doses in a reactor. The production rates and chemical techniques are discussed by Thompson and Muga. ${ }^{3}$ The sample is usually produced in an aluminum-clad "slug" of an oxide or metal alloy of target material. Dissolution is accomplished by removing the aluminum in 6 M NaOH-2 $\mathrm{MNaNO}_{3}$ solution, filtering or centrifuging the insoluble residue containing the transcurium elements away from the aluminate solution, and finally dissolving this residue with strong mineral acid (usually HCl, or occasionally $\mathrm{HCl}$ with a trace of $\mathrm{HF}$ and $\mathrm{HNO}_{3}$ ). These operations are performed by remote control in shielded equipment since the target materials and intermediate isotopes undergo fission while the transcurium elements are being formed The complete separations, including the isolation of a rare-earth fraction and the separation of the lanthanide and actinide fractions, are usually included in the "cave" operation. Procedure 1 in Section VII is typical

\section{COUNTING PROCEDURES AND SOURCE PREPARATIONS}

Counting samples of the transcurium elements are usually prepared "mass-free" or "thın" because there are no stable carriers, of course, and 


\section{VACUUM}

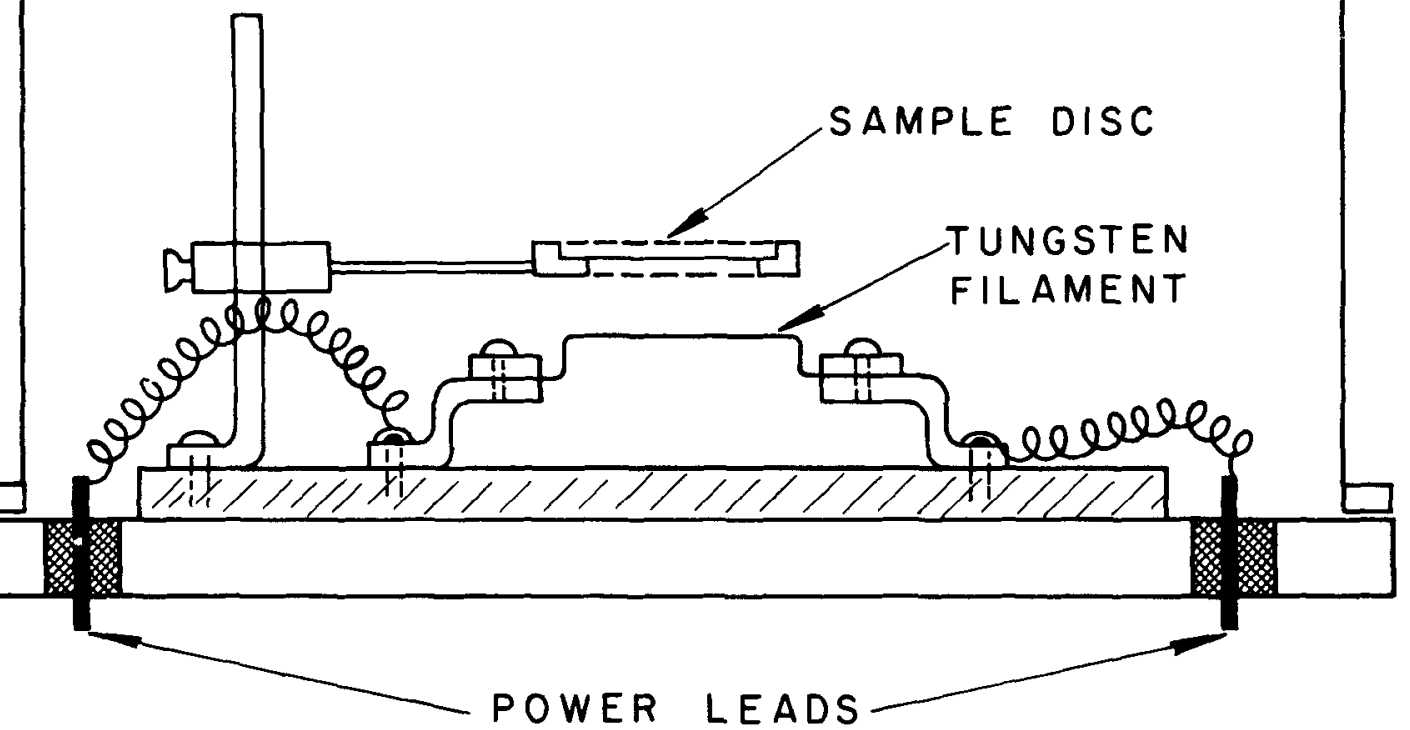

Fig. 9. Schematic diagram of vacuum volatilizer. Carrier-free solutions are evaporated on the tungsten filament, the system is evacuated, and the transcurium elements are volatilized onto the counting disc by passing a short-duration high-current pulse through the tungsten filament.

because some of the most useful measurements involve the a particles which have short ranges. The sample is usually prepared either by evaporating a drop or several drops of column eluate on a plate of platinum or other metal and then performing the counting operations, or by evaporating the pure carrier-free solution onto a tantalum or tungsten filament approximately $5 \mathrm{~mm}$ wide, 30 to $50 \mathrm{~mm}$ long, and $0.1 \mathrm{~mm}$ thick. This filament is placed between electrodes in a vacuum jar a few millimeters away from a $7 / 8$-inch platinum counting disc, as indicated in Fig. 9, and the transcurium element salts (usually oxides) are volatilized onto the counting disc by allowing more than $10 \mathrm{amp}$ of current to flow through the filament for a few tenths of a second. This current raises the filament temperature above $1400^{\circ} \mathrm{C}$ and effectively vaporizes all the transcurium material. Very thin uniform counting 
plates can be prepared in this way; however, the active material will recoil off the plates at an appreciable rate unless they are heated to about $500^{\circ} \mathrm{C}$ in air.

No special counting equipment is used for detection of $\beta$, electroncapture, or a particles. Most tracer work is done with the transcurium elements by utilizing the fact that isotopes of these elements have unique $a-$ particle energies. A particular process or bombardment can be traced by introducing known amounts, measured in terms of counts per unit time, of a specific longer-lived isotope (e.g., $\mathrm{Cf}^{252}$ or $\mathrm{Cf}^{254}$ to trace all $\mathrm{Cf}$ isotopes) and submitting the recovered samples to a pulse-height analysis to determine the ratio of a counts of several isotopes. An a pulse-height analyzer is a valuable and nearly indispensable piece of counting equipment for work with the transcurium elements.

The high spontaneous -fission decay rates are utilized in counting samples of the transcuriurn elements. Spontaneous fission counters are easily constructed by taking advantage of the fact that the specific ionization produced by fission fragments in a counting gas is higher than that produced by a particles. Large electrical pulses are obtained from fission fragments by modifying standard a-particle counters to operate with lower collector voltages. Satisfactory operation is usually obtained with the collector between $1 / 5$ and $1 / 2$ the voltage at which an a plateau if found. The gas flow proportional counters used for both $a$ - and $\beta$-particle counting are especially useful because their collector voltages can usually be varied with ease. Semiconductor detectors and gas scintillation counters can also be used for detecting fission fragments and a particles. 


\section{SPECIFIC SEPARATION PROCEDURES}

\section{Procedure 1}

This procedure is for separation of an impure transcurium element fraction from a pile-irradiated plutonium or americium slug. ${ }^{25}$ The process is designed to be performed on a $50-\mathrm{g}$ aluminum slug containing 0.1 to $1.0 \mathrm{~g}$ of target material. Am and $\mathrm{Cm}$ are also purified.

The slug is placed in a dissolver pot surrounded by an oll bath heated to $80^{\circ} \mathrm{C}$ with an electric immersion heater Then $800 \mathrm{ml}$ of solution $6 \underline{\mathrm{M}}$ in $\mathrm{NaOH}$ and $2 \mathrm{M}$ in $\mathrm{NaNO}_{3}$ is added. The aluminum violently reacts and goes into solution (no heat required after reaction starts). The insoluble material is allowed to settle and the supernate is withdrawn through a sintered stainless steel filter stick. The precipitate is washed twice with $50-\mathrm{ml}$ portions of $2 \mathrm{~N} \mathrm{NaOH}$ saturated with $\mathrm{NH}_{3}$ gas, and then washed with $100 \mathrm{ml}$ of $\mathrm{H}_{2} \mathrm{O}$. The washed precipitate 15 dissolved by adding $50 \mathrm{ml}$ of $12 \underline{\mathrm{M} \mathrm{HCl}-0.1} \underline{\mathrm{M}} \mathrm{HNO}_{3}$ and digesting. After the residue 1 s dissolved, $50 \mathrm{ml}$ of $11 \mathrm{M} \mathrm{LiCl}$ is added and the solution is evaporated to $50 \mathrm{ml}$.

The solution is transferred to a 4 -cm-diam $\times 20-\mathrm{cm}-$ long Dowex- $110 \%$ cross-linked resin column which is heated to $80^{\circ} \mathrm{C}$ with a water jacket. (Free column volume is $\approx 150 \mathrm{ml}$.) The evaporator container and column walls are washed with two $50-\mathrm{ml}$ portions of $10 \underline{\mathrm{M}} \mathrm{LiCl}$ which are allowed to run through the column at the rate of about $2 \mathrm{ml} / \mathrm{min}$. An additional $300 \mathrm{ml}$ of $10 \mathrm{M} \mathrm{LiCl}$ is passed through the column to elute the lanthanides, alkaline earths, and alkali metal ions. The transplutonium actinides are next eluted with $200 \mathrm{ml}$ of $6 \mathrm{~N} \mathrm{HCl}$. Plutonium remains on the column.

The $6 \mathrm{~N} \mathrm{HCl} \mathrm{is} \mathrm{diluted} \mathrm{to} 600 \mathrm{ml}$ and passed through a Dowex-50 12\% resin bed $4 \mathrm{~cm}$ in diam and $20 \mathrm{~cm}$ long. The column is then washed with 300 $\mathrm{ml}$ of $2 \underline{\mathrm{M}} \mathrm{NH}_{4} \mathrm{Cl}$ which removes $\mathrm{Cr}, \mathrm{N}_{1}$, and several other impurities and converts the resin to the $\mathrm{NH}_{4}{ }^{+}$form. The actinides are then eluted with $0.4 \mathrm{M}$ a-hydroxyisobutyric acid adjusted to a suitable $\mathrm{pH}$. The desired elements are collected in four or five "cuts" selected on the basis of the ele- 
ments desired for further work and the number of FCV's predicted from Fig. 7 and the pH. The FCV 1 s $\approx 150 \mathrm{ml}$. The transcurium element fraction thus obtained may be pure enough to be processed without remote-control equipment and is usually further purified by a procedure similar to Procedures 2 and 3 following

\section{Procedure 2}

This procedure was devised to separate the transplutonium elements from day-old fission product samples containing $10^{15}$ to $10^{16}$ fissions. 26 These elements are carried with yttrium or lanthanum fluoride and hydroxide precipitates, which are subsequently dissolved in $\mathrm{HCl}$, the resultant solution is passed through several anion resin columns to remove $U, N o, P u$, and most of the remaining fission products (in particular, $\mathrm{Zr}$ and $\mathrm{Te}$ ) An ethanol-HCl elution from a cation resin column is used to remove the lanthanides.

To prepare the ion exchange columns, the column tıps are plugged with glass wool or sand. A slurry of resin is introduced and allowed to settle, and the supernate discarded. The resin is washed by passing several $\mathrm{ml}$ of eluant through the column. A uniformly deposited bed of resin, free from a1r bubbles or channels, is essential to a successful elution.

1. To an aliquot of the sample in a $40-\mathrm{ml}$ centrifuge tube, add 2 drops each of $10 \mathrm{mg} / \mathrm{ml} \mathrm{Zr}$, Te, and $\mathrm{Sr}$ carriers and $1 \mathrm{drop}$ of $10 \mathrm{mg} / \mathrm{ml} \mathrm{Y}$ carrier. Using phenolphthalein indicator, add $\mathrm{NH}_{4} \mathrm{OH}$ to precipitate the $\mathrm{Y}(\mathrm{OH})_{3}$. Centrifuge, discard the supernate, and wash the precipitate twice with $0.5-1.0$ $\mathrm{ml} \mathrm{H}_{2} \mathrm{O}$

2. Dissolve the precipitate in a minimum amount of $3 \mathrm{M} \mathrm{HCl}$ and transfer to a polyethylene test tube. Add 2 drops conc HF per ml of solution (If the solution contains a large amount of $\mathrm{Fe}$ or $\mathrm{U}$, add enough $\mathrm{HF}$ to de- 


\section{Procedure 2 (Continued)}

colorize the solution, then 2 drops per ml in addition.) Let the solution stand for 5 minutes, centrifuge, discard the supernate, and wash the precipitate with $0.5 \mathrm{ml}$ of $2 \underline{\mathrm{M}} \mathrm{HF}-2 \underline{\mathrm{M}} \mathrm{HNO}_{3}$ solution.

3. Dissolve the fluoride precipitate by adding 1 drop saturated $\mathrm{H}_{3} \mathrm{BO}_{3}$, stirring, and then adding $2 \mathrm{ml}$ conc HCl. Transfer the solution to a $40-\mathrm{ml}$ glass centrifuge tube Add 2 drops of $10 \mathrm{mg} / \mathrm{ml} \mathrm{Sr}$ carrier and then boil the solution briefly. Precipitate the $\mathrm{Y}(\mathrm{OH})_{3}$ with $\mathrm{NH}_{4} \mathrm{OH}$, centrifuge, discard the supernate, and wash the precipitate twice with $0.5-1.0 \mathrm{ml} \mathrm{H}_{2} \mathrm{O}$.

4 Dissolve the precipitate in $3 \mathrm{ml} \mathrm{l0} \underline{\mathrm{M}} \mathrm{HCl}$. Add 1 drop conc $\mathrm{HNO}_{3}$. Transfer the solution to a $5-\mathrm{cm} \times 2-\mathrm{cm}$ Dowex-1 AG anion resin column which has been washed with several column volumes of $10 \underline{M}$ HCl solution containing $0.1 \mathrm{M}^{\mathrm{M}} \mathrm{HNO}_{3}$ Push through with pressure. After adding $1 \mathrm{drop}$ each of $10 \mathrm{mg} / \mathrm{ml} \mathrm{Zr}$ and $\mathrm{Te}$ carriers, pass the solution through two additional $10-\mathrm{cm} \times 8-\mathrm{cm}$ anion columns which have also been treated with $10 \underline{M}$ $\mathrm{HCl}$ containing $0.1 \underline{\mathrm{M}} \mathrm{HNO}_{3}$ (the small column contains $\mathrm{Pu}$ if present in the initial solution).

5. Add $\mathrm{NH}_{4} \mathrm{OH}$ to the combined $10 \mathrm{M} \mathrm{HCl}$ solution to precipitate $\mathrm{Y}(\mathrm{OH})_{3}$. Centrifuge, discard the supernate, and wash the precipitate twice with $0.5 \mathrm{ml} \mathrm{H}_{2} \mathrm{O}$.

6. Dissolve the precipitate in a minimum amount of $0.1 \underline{M} \mathrm{HCl}$ and pass the solution through a $1-\mathrm{cm} \times 2-\mathrm{cm}$ Dowex-50 AG cation resin column which has been previously washed with several column volumes of $0.1 \mathrm{M} H C 1$. Wash the column with $1 \mathrm{ml}$ of $0.1 \underline{\mathrm{M} \mathrm{HCl}}$, then $2 \mathrm{ml}$ of the $0.006 \underline{\mathrm{M}} \mathrm{HF}-0.1 \underline{\mathrm{M}}$ $\mathrm{HCl}$ solution, and finally $1 \mathrm{ml} 0.5 \mathrm{M} \mathrm{HCl}$.

7 Using a transfer pipet and a minimum of $\mathrm{H}_{2} \mathrm{O}$, transfer the cation resin from the $1-\mathrm{cm}$ column to the top of a $12-\mathrm{cm} \times 2-\mathrm{cm}$ Dowex-50 resin column which has been previously washed with several column volumes of the ethanol-HCl elutriant. After the resin has settled, withdraw the excess $\mathrm{H}_{2} \mathrm{O}$ and wash out the column above the resin with a small portion of ethanol- 


\section{Procedure 2 (Continued)}

$\mathrm{HCl}$. Elute the activity with the $20 \%$ ethanol-HCl solution, using sufficient pressure to give approximately 1 drop every 45 seconds. Collect the desired fraction (usually drops 6-25) in a 40-ml centrifuge tube. (See Fig 1 for typical elution positions.)

This solution will be free of most contaminants, however, the column separation can be repeated for complete separation of the lanthanide activities. The pure activities can be separated from each other with Procedure 3.

Note: Several variations of steps 6 and 7 are reported by different workers. Some prefer loading the resin slurry onto the resin bed of the column in step 7. Others prefer to run the solution from step 6 directly into the long column and to follow it with 10 to 20 column volumes of $2 \mathrm{M} \mathrm{HCl}$, then the alcoholic HCl. The $2 \underline{M}$ wash moves the transcurium elements down the column about $10 \%$ of the length and they are less perturbed by the shrinkage and accidental stirring of the resin than otherwise.

\section{Procedure 3}

This procedure is for separating the actinides from each other in solutions free of lanthanides, other mass impurities, and radioactivities. It is similar to the procedure of Thompson et al. ${ }^{6}$ except that it uses a hydroxyisobutyric acid instead of lactic acid, and consequently gives better separations. 27

1 Preparation of resin eluant and equipment.

A. Dowex $-5012 \%$ cross-linked resin, 200-400 mesh spheres (obtained from Bio-Rad Labs., 32nd and Griffin Ave., Richmond, Calif.), is further graded for size by selecting the fraction that settles between 0.5 and $0.25 \mathrm{~cm} / \mathrm{min}$ from water.

B. The graded resin is washed alternately with $12 \underline{\mathrm{M}} \mathrm{HCl}$ and $\mathrm{NH}_{4} \mathrm{OH}$ and finally stored in the ammonium form. 
C. The eluant is prepared from commercial a-hydroxysobutyric acid diluted to $0.4 \mathrm{M}$ with the $\mathrm{pH}$ adjusted between 3.8 and 4.4 to give the desired elution time-peak separation. (See Fig. 7.) Phenol may be added. until the solution is $0.01 \mathrm{M}$ to prevent the growth of mold.

D. Apparatus is set up as in Fig. 5. The column bore is $2 \mathrm{~mm}$ in diam and about $10 \mathrm{~cm}$ long over the capillary region. The tip is plugged with glass wool. The column is heated to the boiling point of trichloroethylene and the bore is filled with distilled water, then small amounts of resin slurry are added to the column and allowed to settle into the bore until a settled bed $5 \mathrm{~cm}$ in height is obtained. The excess distilled water is removed and several $\mathrm{ml}$ of eluant $1 \mathrm{~s}$ added to further remove trace impurities. Just prior to using the column, the eluant reservoir is lowered, the top of the column is washed with distilled water, and a drop or two of distilled water is allowed to run into the column

2 An $\mathrm{HCl}$ or $\mathrm{HNO}_{3}$ solution containing the actinide element mixture is evaporated to near dryness in a $5-\mathrm{ml}$ centrifuge cone, and diluted with $\approx 0.1 \mathrm{ml}$ of hot $0.05 \mathrm{M} \mathrm{HCl}$. This solution is transferred to the resin bed and allowed to run through. The cone and sides of the column above the resin bed are washed with $50 \mu \mathrm{l}$ of $0.05 \mathrm{M} \mathrm{HCl}$ solution which is allowed to run into the resin. The washing procedure is repeated.

3. The centrifuge cone 1 s washed with $50 \mu \mathrm{l}$ of eluant which is then transferred to the column and allowed to run into the column. The first drop to fall from the column after this is "drop 1 " of the elution.

4. The bore of the column above the resin is filled with hot eluant carefully so as to avoid stirring the resin bed, and the eluant reservoir is lifted to provide the desired flow rate (see Fig. 8). Satisfactory separations are obtained with flow rates of $1 / 2$ to 1 drop per minute.

5. Each drop is collected on a platinum plate which is dried under a heat lamp and heated to red heat in an induction heater to remove the last 


\section{Procedure 3 (Continued)}

traces of organic material. Plates are ready to count.

The approximate elution positions can be predicted from the curve in Fig. 7 and from Table II, assuming a 3-drop free column volume; however, slight variations in eluant and resin make it desirable to "calibrate" each column with a tracer of some transplutonium actinide before separations are attempted. If carriers are included in the solution the same procedure can be followed, but the column size should be adjusted to provide $0.4 \mathrm{~cm}^{2}$ of column area for each milliequivalent of carrier, and the length of the column should be at least 10 times the diameter.

\section{Procedure 4}

This procedure separates the actinides from the lanthanides. ${ }^{6}$ Dowex-1 resin is used with an $\mathrm{HCl}$ solution containing the actinide elements, lanthanide activities, and about $\mathrm{l} \mathrm{mg}$ lanthanum carrier.

A. Dowex-1 8\% cross-linked resin, 200-400 mesh spheres, is sizegraded by selecting the fraction that settles from 0.15 to $0.25 \mathrm{~cm} / \mathrm{min}$ in water. The graded resin is washed alternately with $12 \underline{\mathrm{M}} \mathrm{HCl}$ and $\mathrm{NH}_{4} \mathrm{OH}$ and is stored in the chloride form after a final $\mathrm{HCl}$ wash.

B. Eluant is prepared by saturating commercial analytical grade $\mathrm{HCl}$ with $\mathrm{HCl}$ gas. Immersing the bottles in room-temperature tap water helps dissipate the heat. The final concentration of acid at $20-22^{\circ} \mathrm{C}$ will be about $13 \underline{M}$.

C. The column is prepared by attaching a section of 3-mm-diam capillary tubing to a $15-\mathrm{ml}$ centrifuge cone, packing the tip with glass wool, and filling the bore to a height of $5 \mathrm{~cm}$ with the resin. The column should be alternately washed with eluant and water before use. The final wash is made with eluant.

1. The solution to be purified is evaporated to $\approx 30 \mu$ with an air jet in a $5-m l$ centrifuge cone. The cone is placed in an ice-water bath 


\section{Procedure 4 (Continued)}

and the solution saturated with $\mathrm{HCl}$ from a gas cylinder.

2. The solution is transferred to the top of the column. The first drop to fall after this is called "drop 1." The cone is rinsed with $30 \mu l$ of eluant which is transferred to the column. This wash is then repeated. One milliliter of eluant is carefully placed on top of the column and drops are collected through drop 12. The flow rate can be maintained at about 3 minutes per drop with a hypodermic syringe and rubber stopper.

3. After drop 12 has fallen, the eluant is removed above the resin, a $15-\mathrm{ml}$ centrifuge cone is placed under the column, and $1 \mathrm{ml}$ of $10 \underline{M}$ HCL is placed on top of the resin. This is passed through the resin and elutes the transcurium elements. Am, Cm, and the lanthanides are found in drops 1-12. U and Pu (in the IV.or VI oxidation state) remain on the resin and may be subsequently removed.

\section{Procedure 5}

This procedure 27 is for purification of Md recoils produced by a particle bombardment of $\mathrm{Es}^{253}$. It is typical of the catcher forl chemical techniques. Other actinide targets and products are similarly handled.

The target consisted of $\approx 10^{9}$ atoms of $\mathrm{Es}^{253}$ electroplated on a 1/32-1n. $\times 1 / 4-1 n$. area of larger 0.002-1n, -thick gold forl. A 48-Mev a beam was allowed to pass through the gold target forl and "knock off" the $\mathrm{Md}$ atoms onto a 0.0001-1n. -thick gold "catcher" forl.

1. The catcher foll was dissolved in aqua regia, and the gold extracted with an equal liquid volume of ethyl acetate for $\approx 1 \mathrm{~min}$.

2. The aqueous phase was passed through a $2-\mathrm{mm}-\mathrm{d}$ am $\times 1-\mathrm{cm}-$ long bed of Dowex-1 anion resin heated to $87^{\circ} \mathrm{C}$ (see Fig. 9), at a rate of about five 30- $\mu$ l drops per minute. The original volume plus 5 drops containing the actinide elements was collected and evaporated with a jet of hot air. 


\section{Procedure 5 (Continued)}

3. Tracer Es ${ }^{253}$ was added and the solution was passed through a 2-mm-diam by 5-cm-long bed of Dowex-50 $\times 12$ ammonia-form cation resin heated to $87^{\circ} \mathrm{C}$. The adsorbed actinides were selectively eluted with a $0.4 \underline{\mathrm{M}}$ solution of a-hydroxyisobutyric acid which had been adjusted to $\mathrm{pH} \approx 4.0$ with ammonium hydroxide. The eluant was passed through the column. at a

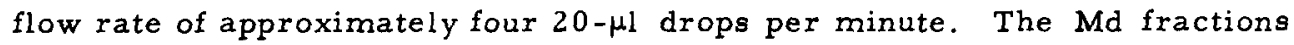
were collected in drops 8-13, Fm in drops 15-19, Es in drops 27-31, and Cf in drops $39-47$.

\section{Procedure 6}

This procedure is for oxidation and extraction of $\mathrm{Bk}$ from a solution containing lanthanides and actinides. ${ }^{9}$ No carriers are used.

1. The solution is evaporated to near dryness two or three times with $16 \underline{\mathrm{MNO}_{3}} \mathrm{HNO}_{3}$. After the last evaporation, the sample is diluted and $\mathrm{KBrO}_{3}$ is added to make the solution $10 \mathrm{M}$ in $\mathrm{HNO}_{3}$ and $1 \underline{\mathrm{M}}$ in $\mathrm{KBrO}_{3}$ (Note 1). The volume of the solution is measured in milliliters (called $\mathrm{V}$ in the following).

2. $\mathrm{V} \mathrm{ml}$ of $0.15 \mathrm{M}$ HDEP (Note 2)-heptane solution is washed three times with $\mathrm{Vml}$ of freshly prepared $10 \underline{\mathrm{M}} \mathrm{HNO}_{3}-1 \underline{\mathrm{M}} \mathrm{KBrO}_{3}$, for 3 minutes each time. The aqueous phases are discarded.

3. The solution from step 1 is contacted with the organic phase from step 2 for 3 minutes and the phases are separated.

4. The organic phase from step 3 is washed twice for 3 minutes with $\mathrm{V} \mathrm{ml}$ of freshly prepared $10 \mathrm{M} \mathrm{HNO}_{3}-1 \underline{\mathrm{M}} \mathrm{KBrO}_{3}$. The wash solutions are discarded.

5. The washed organic phase from step 4 is back-extracted for $3 \mathrm{~min}$ utes into $\mathrm{V} \mathrm{ml}$ of freshly prepared $10 \underline{\mathrm{M}} \mathrm{HNO}_{3}-1.5 \underline{\mathrm{M}_{2}} \mathrm{O}_{2}$ solution. The organic phase is discarded.

6. The aqueous phase from step 5 is washed, first with $\mathrm{V} \mathrm{ml}$ of $0.15 \mathrm{M}$ 


\section{Procedure 6 (Continued)}

HDEP - heptane for 3 minutes, and then with $\mathrm{V} \mathrm{ml}$ of heptane for 3 minutes. The organic phases are discarded, the aqueous phase contains $\approx 97 \%$ of the $B k$, decontaminated by factors of $\approx 10^{4}$ from all other lanthanides and actinides except $\mathrm{Ce}$, and by factors of $\approx 10^{6}$ from $\mathrm{Cm}$ and $\mathrm{Cf}$. (Note 3.)

\section{Notes}

1. $0.1 \mathrm{M} \mathrm{KBrO}_{3}$ may be substituted at all points calling for $1 \underline{\mathrm{M}} \mathrm{KBrO}_{3}$ with little or no decrease in yield.

2. HDEP is di(zethylhexyl) orthophosphoric acid, $\left[\mathrm{C}_{8} \mathrm{H}_{17} \mathrm{O}\right] 2$ $\mathrm{PH}(\mathrm{OH})$, and is available in impure form from the Victor Chemical Works. It is purified by the procedures reported by D.C. Stewart and H. W. Crandall, J. Am. Chem. Soc. 73, 1377 (1951).

3. Cunningham and Wallmann ${ }^{11}$ have used a procedure similar to this for extracting submicrogram quantities of $\mathrm{Bk}$ from $\mathrm{Cf}$ and $\mathrm{Cm}$. Solution volumes were reduced to submicroliter quantities.

\section{Procedure 7}

This procedure is for removal of macro impurities from tracer transcurium samples. ${ }^{17}$

1. A jacketed column for operation at $87^{\circ} \mathrm{C}$ is prepared. Dowex-50 AG $4 \%$ cross-linked resin (settling rate 0.5 to $0.25 \mathrm{~cm} / \mathrm{min}$ ) is used in the $\mathrm{H}^{+}$form ( $\mathrm{HCl}$ wash last), and prepared otherwise as in Procedure 3, steps $1 \mathrm{~A}$ and $1 \mathrm{~B}$. The column bore $1 \mathrm{~s} 3 \mathrm{~mm}$ in diam and the tip consists of a platinum rod fused to the glass capillary and bored out with a No. 64 drill. This tip delivers uniform $13-\mu 1$ drops.

2. The solution to be purified is prepared so as to be $0.1 \mathrm{M}$ in $\mathrm{HCl}$ and then allowed to pass through the column. The column walls are rinsed with several $100-\mu l$ portions of $0.1 \underline{\mathrm{M}} \mathrm{HCl}$.

3. About $1 \mathrm{ml}$ of $2 \mathrm{M} \mathrm{HCl}$ is carefully introduced above the resin bed 
and forced through the resin at the rate of about 6 drops per minute until 50 drops have been collected.

4. The remaining $2 \underline{\mathrm{M}} \mathrm{HCl}$ is withdrawn and $\mathrm{l} \mathrm{ml}$ of $6 \underline{\mathrm{M}} \mathrm{HCl}$ is added and forced through the resin at the rate of 6 drops per minute until 30 or 40 drops are collected. The transcurium elements elute close together araund drop 80 (counting from the beginning, including the 50 drops from step 3 ). Other cations elute as indicated in Table III. 
Table III. Order of elution of cations from resin column in Procedure 7.

\section{Table III. Order of elution of cations from resin column in Procedure 7.}

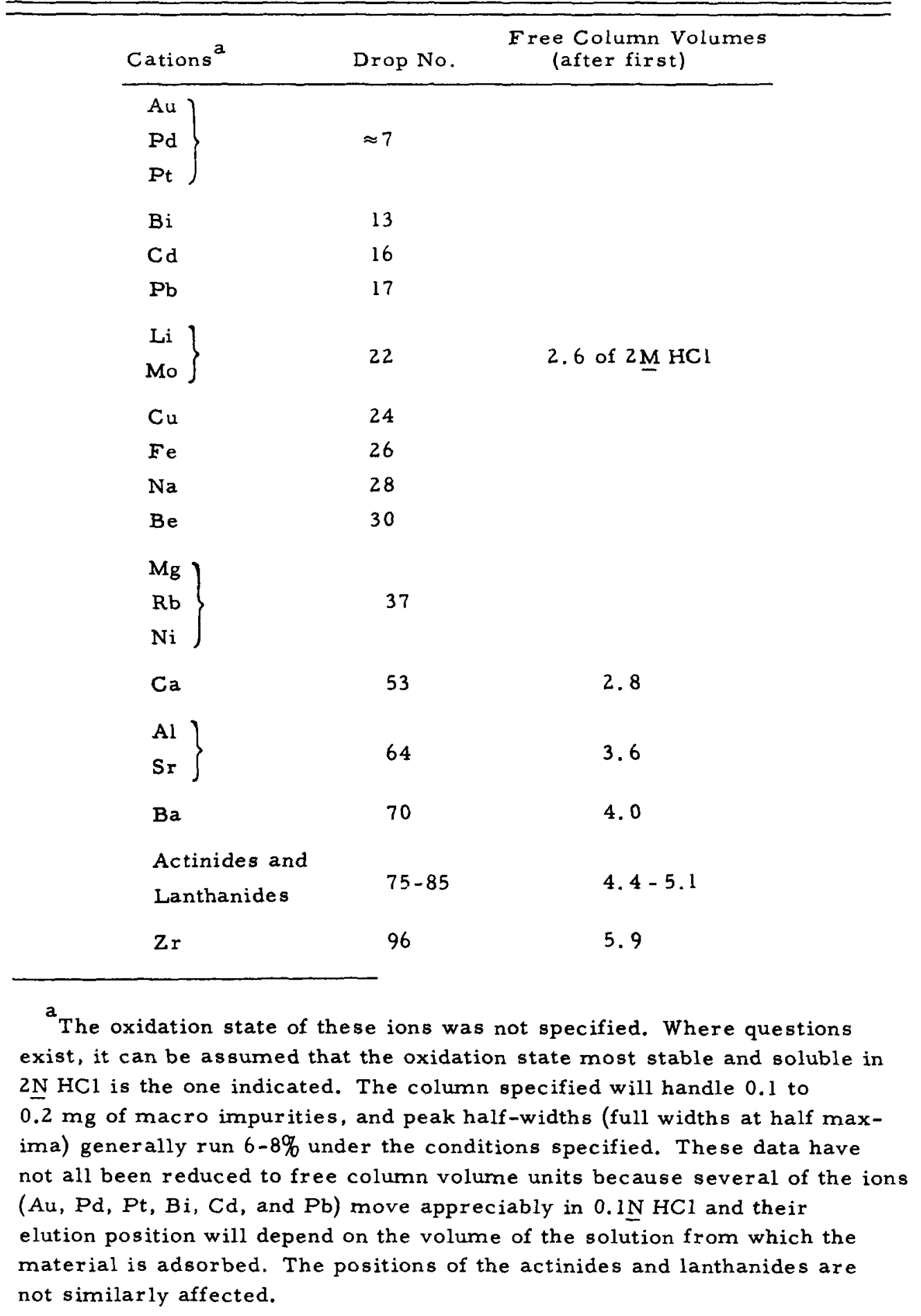




\section{REFERENCES}

1. S. G. Thompson, "The Discovery of the Transuranium Elements: Their History and a Presentation of the Different Methods Used in Their Discovery," UCRL-8615 (April, 1959).

2. B. B. Cunningham, J. Chem. Educ. 36 (January, 1959).

3. S. G. Thomps on and M. Louis Muga, "Methods of Production and Research on Transcurium Elements." Proc. U.N. Intern. Conf. Peaceful Uses Atomic Energy, 2nd, Geneva, 1958, 15/P/825.

4. G. T. Seaborg, "The Transuranium Elements," Addison-Wesley Publishing Co., Inc., Reading, Mass., 1958.

5. J. K. Katz and G. T. Seaborg, "Chemistry of the Actinide Elements," Methuen and Co., Ltd., London, 1957.

6. S. G. Thompson, B. G. Harvey, G. R. Choppin, and G. T. Seaborg, J. Am. Chem. Soc. 76, 6229 (1954).

7. S. G. Thompson, B. B. Cunningham, and G. T. Seaborg, J. Am. Chem. Soc. 72, 2798 (1950).

8. J. Fuger, J. Inorg. \& Nuclear Chem. 5, 332-8 (1958).

9. D. F. Peppard, J. W. Moline, and G. W. Mason, J. Inorg. \& Nuclear Chem. 4 , 344-8 (1957).

10. D. F. Peppard, G. W. Mason, W. J. Driscoll, and S. McCarty, J. Inorg. \& Nuclear Chem. 12, 14l-8 (1959).

11. B. B. Cunningham and J. C. Wallmann, unpublished data (1960).

12. G. F. Best, E. Hesford, and H. A. C. McKay, J. Inorg. \& Nuclear Chem. 12, 136-40 (1959). 
13. E. K. Hulet, U.S. Patent 2,909, 405 (1959).

14. L. B. Magnussen and M. L. Anderson, J. Am. Chem. Soc. 76, 6207 (1954).

15. A. M. Poskanzer and B. M. Foreman, Jr., paper presented at 136th National Meeting of the American Chemical Society, New York, Sept., 1959, to be published.

16. H. L. Smith and D. C. Hoffman, J. Inorg. \& Nuclear Chem. 3, 243-7 (1956).

17. J. P. Surls and G. R. Choppin, J. Inorg. \& Nuclear Chem. 4, 62-73 (1957).

18. E. K. Hulet, R. G. Gutmacher, and H. S. Coops, "Group Separation of the Actinides from the Lanthanides by Ion Exchange, "UCRL-5639 (1960).

19. J. Milsted, Atomic Energy Establishment, Harwell, England, private communication to S. G. Thompson reported in reference, 5 above.

20. L. Phillips and R. Gatti, Univ. Calif., Berkeley, unpublished data (1960).

21. G. R. Choppin, B. G. Harvey, and S. G. Thompson, J. Inorg. \& Nuclear Chem. 2,66 (1956).

22. J. Milsted and A. B. Beadle, J. Inorg. \& Nuclear Chem. 3, 248 (1956).

23. W. E. Nervik, J. Phys. Chem. 59, 690 (1955).

24. A. Ghiorso and T. Sikkeland, "Heavy Ion Reactions with Heavy Elements," Proc. U.N. Intern. Conf. Peaceful Uses Atomic Energy, 2nd, Geneva, 1958, 15/P/2440.

25. G. H. Higgins and W. W. T. Crane, Proc. U.N. Conf. Peaceful Uses Atomic Energy, 2nd, Geneva, 1958, 17/P/1883.

26. D, C. Hoffman, J. W. Barnes, H. L. Smith, and W. R. Daniels, unpublished procedure used at Los Alamos Scientific Laboratory (1958).

27. A. Ghiorso, B. G. Harvey, G. R. Choppin, S. G. Thompson, and G. T. Seaborg, Phys. Fev. 98, 1518 (1955). 